\title{
Spatio-Temporal Regulation of PKC Isoforms Imparts Signaling Specificity
}

\author{
Arkajyoti Mukherjee, Sayoni Roy, Bhaskar Saha* and Debasri Mukherjee* \\ National Centre for Cell Science, Pune, India \\ Keywords: PKC isoforms, spatio-temporal regulation, subcellular distribution, PKC-signaling module, intracellular \\ pertubators
}

\section{INTRODUCTION}

Nishizuka and colleagues discovered protein kinase C (PKC) as a calcium-dependent, lipid cofactorsensitive protein kinase (1). Initially known as the only physiological effector for tumor-promoting phorbol esters, this ubiquitous enzyme eventually took center stage in cellular signaling. Part of the AGC kinase branch of the kinome, PKC is a family of serine/threonine kinases comprising 11 isoforms encoded by 9 genes and grouped into 4 classes - classical (cPKCs- $\alpha, \beta \mathrm{I}, \beta \mathrm{II}, \gamma$ ), novel (nPKCs- $\delta, \epsilon, \eta, \theta$ ), atypical (aPKCs- $\zeta, \mathrm{t} / \lambda$ ), and $\mathrm{PKC} \mu$ (a form between novel and atypical isoforms)

OPEN ACCESS

Edited by:

Diana Bahia,

Universidade Federal de Minas

Gerais, Brazil

Reviewed by:

Michael Freeley,

Trinity College Dublin, Ireland

*Correspondence:

Bhaskar Saha

sahab@nccs.res.in;

Debasri Mukherjee

mukherjee.debasri@gmail.com

Specialty section:

This article was submitted to

Microbial Immunology,

a section of the journal

Frontiers in Immunology

Received: 30 November 2015

Accepted: 29 January 2016

Published: 17 February 2016

Citation:

Mukherjee A, Roy S, Saha B and Mukherjee D (2016) Spatio-Temporal Regulation of PKC Isoforms Imparts

Signaling Specificity.

Front. Immunol. 7:45.

doi: 10.3389/fimmu.2016.00045
(Box 1). Their considerable structural homology, overlapping substrate specificities, and biochemical properties indicated at least partial enzymatic redundancy and rendered the task of identifying isoform-specific functions challenging. The initial phase of PKC research correlated the unique structural features of the isoforms with their functions (Box 1) (2). But, with their structural overlaps and hugely varying functions in different models, specificity of the isoforms became a confounding puzzle demanding stringent isoform-specific regulation to avoid functional redundancy. To define this stringency, subsequent PKC research focused on the upstream and downstream regulatory mechanisms $(3,4)$, highlighting the importance of subcellular distribution as a function of time (5). As simultaneous activation of all PKC isoforms would be energetically and spatially conflicting for decoding the message received by the cell surface receptor, cell type, and stimulus-specific selective and sequential activation deemed justified (6). The recent phase of PKC research propounds a $\mathrm{PKC}$-signaling module $(7,8)$ wherein an inter-isoform network regulates the PKC isoforms' activity (Box 2; Figure 1B). Here, we propose activator- and cofactor-specific sequential activation of PKC isoforms in a spatio-temporal model wherein selective subcellular compartmentalization quantitatively determines the isoform-specific effector functions.

\section{STRUCTURAL BIAS TO PKC FUNCTION?}

Structural reconfigurations of the PKC isoforms play a central role in orchestrating their spatial distribution and activation (15). C1 domain ligands - diacylglycerol (DAG) and phosphatidylserine (PS) - recruit PKC by altering the surface properties of the domain to favor membrane penetration. Studies on GFP-PKC with the fluorescent phorbol ester analog sapintoxin-D showed differential subcellular localization of $\mathrm{C} 1$ ligands determining subcellular targeting of PKCs (16). The nPKC C1B domain has a 100-fold higher affinity for DAG compared to cPKCs due to an invariant tryptophan residue at position 22 as opposed to a tyrosine in case of cPKCs resulting in rapid plasma membrane localization for $\mathrm{cPKCs}$ versus slower and sustained Golgi localization for nPKCs (17). The $\mathrm{C} 2$ domain functions as a $\mathrm{Ca}^{2+}$-regulated membrane anchor in $\mathrm{cPKCs}(6,15)$ while regulating protein-protein interactions and spatial distribution through phosphotyrosine-binding modules in 


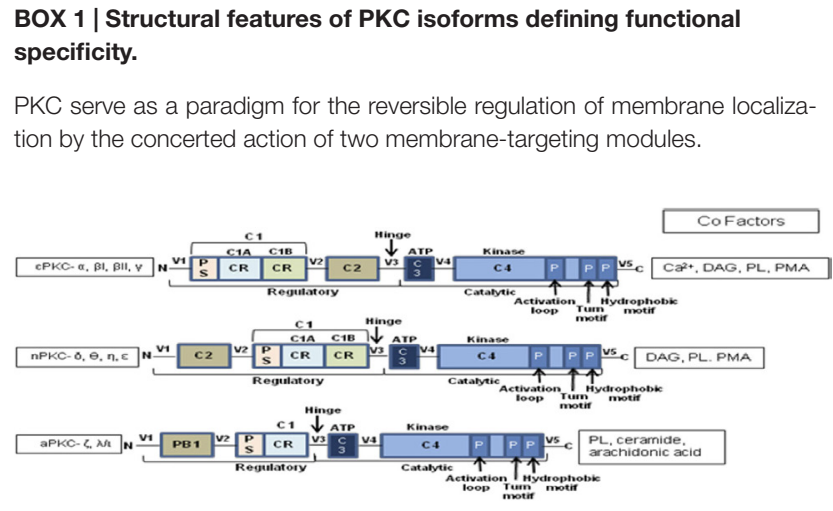

C1: a cysteine-rich region of approximately 50 residues present in all PKC isozymes. In cPKCs and $\mathrm{nPKCs}$, it is present as a tandem repeat $\mathrm{C} 1 \mathrm{~A}$ and C1B. aPKCs contain a single copy of the domain termed atypical because it does not bind phorbol esters. The domain contains two pulled apart $\beta$-sheet forming the ligand-binding pocket. Two zinc atoms are coordinated by two histidines and six cysteines at opposite ends of the primary sequence stabilizing the domain. In aPKCs, one face of the ligand-binding pocket is compromised, so that the module cannot bind phorbol esters or DAG.

Ligand binding dramatically alters the surface properties of the module (C1B). The ligand caps the hydrophilic ligand-binding pocket, so that the top-third of the $\mathrm{C} 1$ domain presents a continuous hydrophobic surface thus achieving membrane targeting by simply altering membrane properties.

C2: an independent membrane-targeting module that binds calcium in CPKCs, but not in nPKCs. C2 domain is a $\beta$-strand rich globular domain with loops formed by sequences at opposite ends of the primary structure. Two topological variants exist - Type I for domains that follow the C1 domain (cPKCs) and Type II for domains that precede C1 (nPKCs). In the calciumresponsive $\mathrm{C} 2$ domains of $\mathrm{cPKCs}$, the pocket is lined by multiple aspartic acid residues that coordinate two to three calcium ions that act as a bridge between the $\mathrm{C} 2$ domain and the phospholipid head groups of the membrane.

CR, cysteine rich; PS, pseudosubstrate; DAG, diacylglycerol; PMA, phorbol-12-myristate 13-acetate; PB1, Phox-Bem 1; C, constant regions; V, variable regions.

nPKCs $(18,19)$. The aPKCs are not responsive to either DAG or $\mathrm{Ca}^{2+}$ and instead possess a Phox-Bem (PB) 1 domain that facilitates interactions with scaffolding proteins leading to constitutive activation (20). Phosphorylation plays a key role in determining the cellular levels of PKC rendering them catalytically competent and protecting them from degradation (17). Classical and novel PKCs are constitutively phosphorylated at three conserved residues: the activation loop - the first rate-limiting step governed by phospho-inositide-dependent kinase (PDK)-1 that aligns residues within the active site for catalysis, followed by phosphorylation at the turn motif and autophosphorylation of the hydrophobic loop. For cPKCs and nPKCs, these phosphorylation events require mTORC2. Phosphorylation at the hydrophobic motif controls the stability of the enzyme promoting degradation on dephosphorylation (17). A phosphomimetic glutamic acid prevents phosphorylation at the hydrophobic motif of aPKCs. Although catalytically competent, these phosphorylated PKCs remain inactive in the cytosol due to binding of the pseudosubstrate to its kinase domain (Figure 1A) until appropriate cofactor interaction provides the necessary energy to expel the

\section{BOX 2 | Chronological epochs of PKC research.}

1977-1987: introducing PKC

- Discovery of PKC by Nishizuka and colleagues (1).

- Structural analysis of the PKC isoforms.

- Takai et al. showed PKC to be reversibly activated by $\mathrm{Ca}^{2+}$ phospholipid and DAG (9).

- Identification of PKC as a target for phorbol ester class of tumor promoters by Castagna et al. (10).

- Discovery of the pseudosubstrate region by House and Kemp (2).

- 1988-1997: the decade of elucidation of PKC structure-function relationship

- Elucidation of the structural basis of PKC function.

- Identification of receptors for activated C-kinases by Mochly-Rosen and coworkers (11).

- First report by Nishizuka about the role of PKC in cellular signaling (3).

- In 1994, Dekker and Parker for the first time raised the question of specificity of PKC isoforms (4).

- Cloning of first RACK by Mochly-Rosen et al. (12).

- Role of anchoring protein in localization of PKCs (5).

- For the first time, the role of binding proteins in PKC isoform-specific functions was suggested.

1998-2007: the decade of studies on the spatio-temporal regulation of PKC isoforms

- Identification of PKC anchoring proteins as a means for isozyme selectivity by Mochly-Rosen and colleagues in 1998 (13).

- Detection of substrates that interact with C-kinases (STICKs) through overlay assay by Jaken (14).

- Compartmentalization of PKC through binding proteins and substrates.

- Studies on the temporal kinetics of PKC function.

- Elucidation of cell and stimulus-specific actions of PKC isozymes.

2008-present: inter-PKC regulation and PKC-signaling module

This is the decade where the concept of inter-PKC regulation in calibrating receptor triggered effector functions is gaining popularity leading to the possible build-up of a PKC-signaling network in space-time coordinates.

pseudosubstrate and activate PKC. So, the key to functional specificity in vivo may lie in the isoforms' primary structure and the cofactors governed conformational plasticity. Yet, their promiscuity in vitro suggests involvement of factors beyond the primary structure leading to the studies on the spatio-temporal regulation of these isozymes.

\section{PKC ISOFORM FUNCTIONS IN SPACE-TIME COORDINATES}

Functional specificity of the PKC isoforms depends on the proximity to their substrates in specific intracellular compartments effected through multiple binding proteins that also determine the precise duration and amplitude of $\mathrm{PKC}$ activity thus providing a mechanism for integrating PKC-mediated signaling with other cellular activities. PKC $\beta \mathrm{I}$ interacts with Bruton's tyrosine kinase to positively regulate JNK signaling and cytokine gene expression in mast cells $(6,21)$. Partition defective-3 (PAR3) protein interacts with $\mathrm{PKC} \zeta$ to activate pathways leading to embryonic polarity and asymmetric cell division $(6,22)$, whereas PAR4 inactivates PKC $\zeta$ leading to apoptosis $(6,23)$. Ras-related nuclear protein-binding protein-9/10 integrates PKC $\delta$ and $\gamma$ signals to 

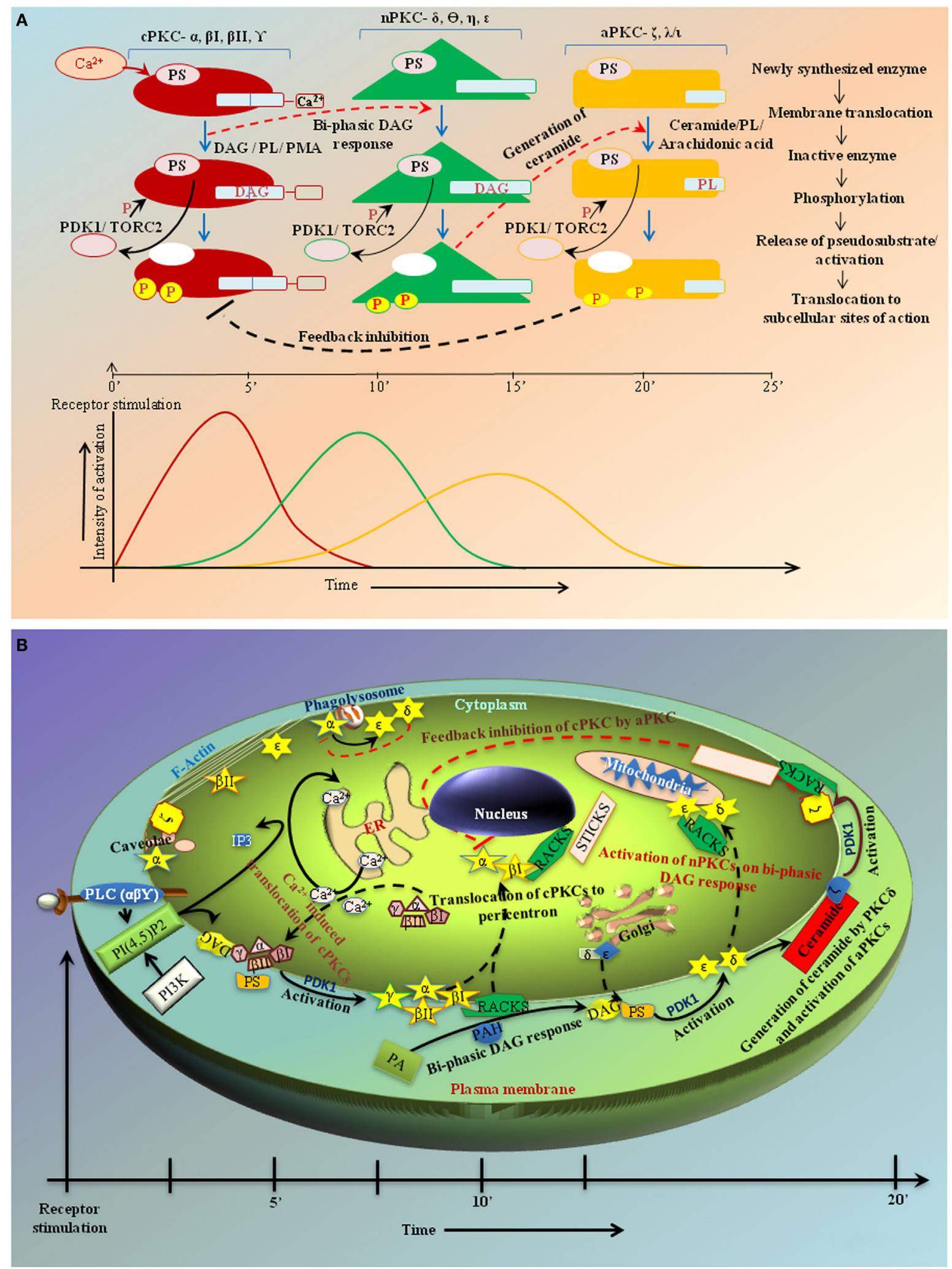

FIGURE $1 \mid$ Continued 


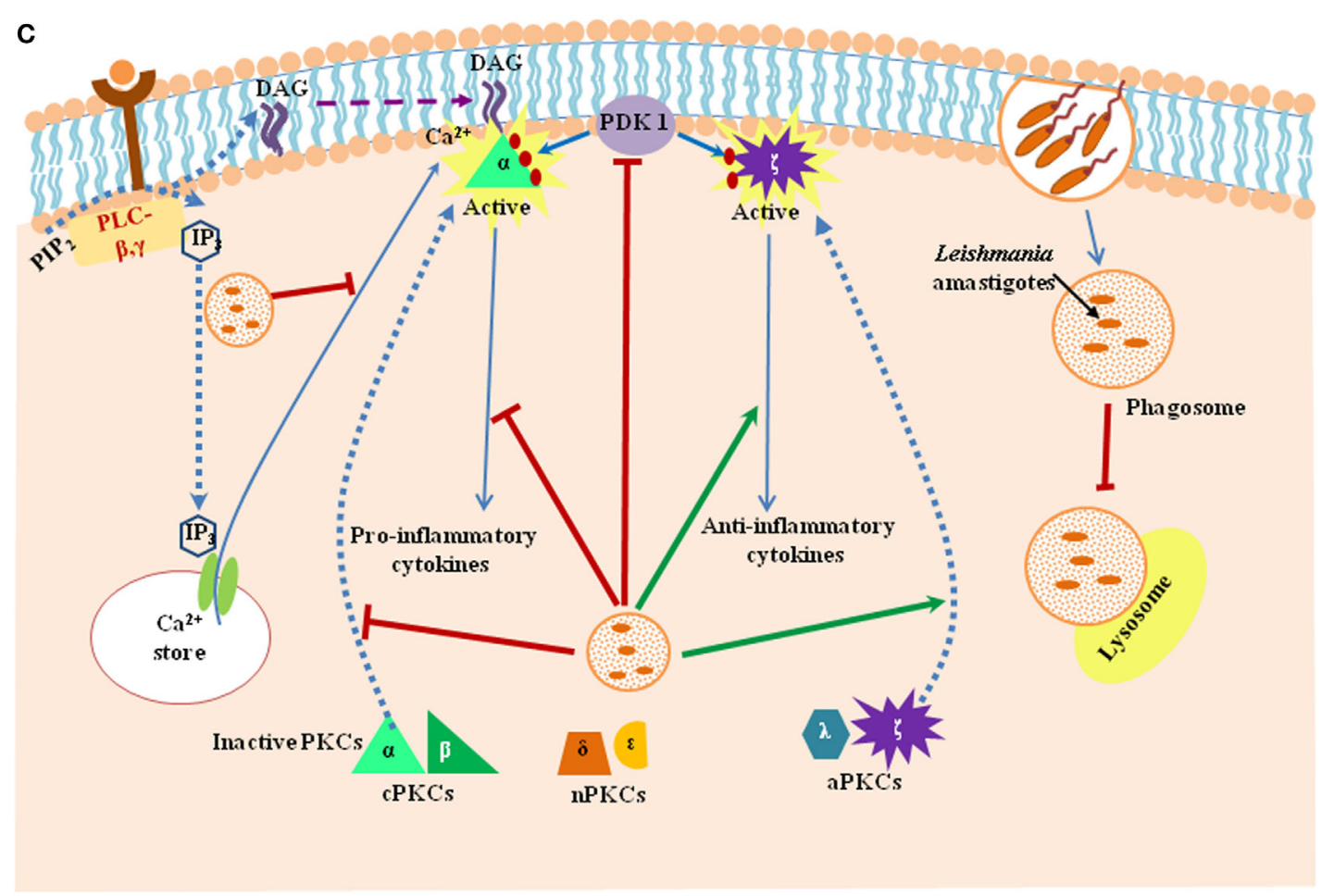

FIGURE 1 | (A) Hypothetical figure showing sequential activation of the PKC isoforms in response to receptor-stimulus coupling. Analyses from various studies indicate that in cases where a single stimulus activates multiple isoforms of different classes the classical PKC isoforms are usually activated first and to the greatest degree followed by the novel and atypical forms. (B) Kinetics of activation and subcellular distribution of PKC isoforms. The various classes of PKC isoforms are localized at different subcellular sites both prior and post activation. They are translocated to the membrane for activation in response to their respective cofactors. Post activation, the isoforms are translocated to specific subcellular locations by their binding partners, which bring them close to their respective substrates. DAG, diacylglycerol; IP3, inositol tri-phosphate; PA, phosphatidic acid; PAH, phosphatidic acid hydrolase; PI3K, phosphatidyl inositol-3-kinase; PLC, phospholipase C; PKC, protein kinase C; PhosIns(4,5)P2, phosphatidyl-inositol-4,5-bis phosphate; RACK, receptors for activated C-kinases; STICK, subtrates that interact with C-kinases. (C) Modulation of PKC isoforms by Leishmania infection. The figure shows modulation of PKC isoforms by Leishmania as it enters a host cell, for instance, macrophages, by preventing phagosome maturation. It interferes with the translocation of isoforms to membranes and inhibits PDK-1. It inhibits Ca ${ }^{2+}$ efflux to prevent DAG-mediated activation of cPKCs $\alpha$ and $\beta$, which are involved in proinflammatory cytokine production thus resulting in disease progression concomitantly enhancing PKC $\delta$ - and $\zeta$-mediated production of anti-inflammatory cytokines to suppress host immune response conducing in parasite survival.

dictate efficient regulation of dopaminergic D1 receptor signaling (24). In CHO cells, initial phorbol 12-myristate 13-acetate (PMA) treatment translocates and colocalizes receptor for activated C-kinases (RACK) 1 and PKC $\beta I$ I to the cell periphery that later move to the perinuclear area (25). Thus, RACK-PKC complex can move from one cellular site to another likely resulting in different molecular events at each site depending on the available substrate. PKC€ interacts specifically with filamentous actin through a binding site located between its two cysteine-rich regions to enhance glutamate exocytosis from nerve terminals (26). Notwithstanding the considerable stimulus and cellular variability in their subcellular distribution, certain PKC isoforms exhibit unique localizations. PKC $\theta$ is redox dependently recruited to the plasma membrane of naive T-cells (27). The scaffolding protein A-kinase anchor protein (AKAP) 450 (25) associates with nascent PKC€ within Golgi/centrosome membranes and dissociates on maturation of PKCe (17). PKC $\zeta$ shows a remarkable range of functions reflecting its multiple cellular locations and interacting partners (28). Interactions with binding partners sometimes also affect $\mathrm{PKC}$ pharmacological profile like AKAP-79 protecting PKC from certain ATP competitive inhibitors and altering the susceptibility of PDK-1 to ATP analog inhibitors (29). These observations indicate that the structural features determine the isoforms' translocation and activation pattern, whereas the binding proteins contribute plasticity and specificity.

As multiple PKC isoforms may be activated by a single stimulus, it is logical to assume that differential activation dynamics can impose specificity. Following receptor ligation, the isoforms exhibited differences in activation kinetics and subcellular localization. The kinetics of $\mathrm{Ca}^{2+}$-induced translocation triggered by the $\mathrm{C} 2$ domain is faster than that triggered by the $\mathrm{C} 1$ domain (30) (Figure 1A) indicating a possible sequential activation pattern (31) guided by stimulus specificities in many cell types including macrophages and T-cells $(8,31)$. Indeed, studies in chick muscle cells have shown short-term stimulation to initially trigger PKC $\alpha / \beta$ membrane translocation followed by PKC $\delta$ to a lesser degree (32). PKC $\delta$-activated acid sphingomyelinase cleaves sphingomyelin releasing ceramide that activates $\mathrm{PKC} \zeta$ and inactivates the $\mathrm{cPKCs}$ (15). These observations support the "sequential 
PKC isoform activation" hypothesis and an inter-isoform regulation (Figure 1A).

\section{INTER-ISOFORM REGULATION AND THEIR SITES OF PERTURBATION}

Coordination between the concomitantly expressed and activated PKC isoforms within a temporal framework seems to be regulated by transphosphorylation of the isoforms (33). Following receptor stimulation, classical isoforms are acutely activated as the release of calcium is fast and transient. Calcium sequestration into the endoplasmic reticulum is also rapid (Figure 1B), so deactivation of the classical isoforms likely occurs earlier than the others. Studies have noted a feedback inhibition of cPKCs on activation of novel and atypical isoforms $(8,15)$. PKC $\delta$ and $\epsilon$ have opposing effects in multiple pathological conditions, including cardiac ischemia, cancer, apoptosis, and cell proliferation (34). During endosome formation in phagocytic cells, the initial calcium burst activates the PKC $\alpha$ leading to initiation of phagosome formation (35). This is sequentially followed by translocation and activation of PKC $\delta$ and $\epsilon$ that play a role in phagosome maturation and lysosomal fusion (36). PKC $\alpha$ can phosphorylate PKCe, so it is possible that the effects of PKC $\alpha$ are shared by PKCe (37). Ceramide generated by $\mathrm{PKC} \delta$ activates $\mathrm{PKC} \zeta$ that inhibits $\mathrm{PKC} \alpha / \beta \mathrm{II}$ at the perinuclear space $(15,38)$. PKC $\zeta$ has constitutive kinase activity that can activate other PKC isoforms. Sequential activation of PKC isoforms thus explains the dynamic modulation of cellular responsiveness dictated by the strength of stimulus (Figure 1B). Following TCR activation, PKC $\alpha$ acts upstream of PKC $\theta$ to activate NFKB (39). Inhibition of PKC $\theta$ abrogates the $\mathrm{PKC} \alpha$ response indicating presence of a feedback loop between the isoforms or, as proposed here, a sequential activation of PKC $\alpha$ and PKC $\theta$. Conversely, PKC $\theta$ and PKC $\beta$ seem to have physiologically redundant roles in TCR/CD28-dependent NFKB and NFAT transactivation in primary mouse $\mathrm{CD}^{+} \mathrm{T}$ cells $(40)$. In intestinal epithelium, PKC $\alpha$ downregulates while PKCe upregulates cyclin D1 thus contributing to the opposing effects of these isoforms in tumor progression (41). nPKC isoforms are sequentially recruited to the immunological synapse with PKCe and $\eta$ being recruited first followed by PKCO (42). Opposing effects of PKC $\eta$ and $\mathrm{PKC} \theta$ on relative numbers of $\mathrm{CD} 4^{+}$and $\mathrm{CD}^{+} \mathrm{T}$ cells have been observed in mice (43). PKC $\alpha$ and PKC $\beta$ cooperate functionally in CD3-induced de novo IL2 mRNA transcriptional transactivation in primary mouse $\mathrm{T}$ cells independently of the actions of PKCO (44). PKCe acts upstream of PKC $\alpha$ in the signal transduction of ischemic preconditioning of human myocardium (45). These inter-PKC regulations through feedback loops and sequential activation constitute a functioning PKC module. Mechanistically, an adaptor with dynamically controlled multiple scaffolds may connect one PKC isoform to the next.

\section{DIFFERENTIAL PKC ISOFORM REGULATION IN INFECTION}

With so many available isoforms, $\mathrm{PKC}$ is an ideal candidate for intracellular perturbators (Figure 1C). Reciprocal action of PKC isoforms has been observed in many infection and disease models. Histone deamination in neutrophils during pathogen infection or chronic inflammation is activated by PKC $\zeta$ while PKC $\alpha$ inhibits it (28). In bone marrow-derived mast cells (BMMs), PKC $\alpha$ and $\theta$ positively regulate IL6 and TNF $\alpha$ production against filarial nematode Acanthocheilonema viteae infection, whereas PKC $\beta$ and $\epsilon$ act as negative regulators (46). cPKC activation seems to be associated with proinflammation as evident by the activation of these isoforms on coincubation with IFN $\gamma$ (47). In Mycobacterium tuberculosis-infected macrophages, $\mathrm{PKC} \alpha$ upregulates proinflammatory response in conjugation with TLR2 on pretreatment with arabinosylated lipoarabinomannan (48). While $\mathrm{PKC} \alpha / \beta$ mediates $\mathrm{CD} 40$-induced p38MAPK phosphorylation and IL-12 expression, PKC $\delta$ and $\zeta$ inhibit it reciprocally by enhancing ERK1/2 phosphorylation and IL-10 production (8). PKC $\alpha$ degrades periphagosomal F-actin required for phagosomal maturation (49). This is key to the survival or elimination of the pathogens, which are either phagocytosed or internalized via receptor-mediated endocytosis. Infection might cause impairment of $\mathrm{Ca}^{2+}$-host signal transduction, which in turn may affect classical PKC isoforms. Leishmania donovani infection or recombinant IL-10 treatment of macrophages inhibits both the activity and expression of the cPKC isoforms (50). Leishmania major also impairs $\mathrm{PKC} \alpha, \beta \mathrm{I}$, $\beta \mathrm{II}$ isoforms while enhancing $\mathrm{PKC} \delta$ and $\zeta$ isoforms in macrophages $(8,37)$. Increased generation of membrane ceramide (51) and concomitant cholesterol extrusion (52) may cause the inhibition of $\mathrm{PKC} \alpha / \beta$ and activation of PKC $\zeta$ in macrophages during Leishmania infection (8). Comparison between DAG and ceramide elucidates the different kinetics of aPKC isoforms from the other two. Ceramide activates the alternate signaling pathways leading to anti-inflammatory responses. PKC $\zeta$ has been shown to be involved in the activation of arginase I, the enzyme responsible for inhibition of iNOS and inflammatory responses toward parasites (53). Intracellular pathogens can interfere with any of these mechanisms in order to tune the PKC-mediated signaling pathways according to their convenience (Figure 1C). Being least specific in regards to cofactor and activator requirements, nPKCs play a dual role in inflammation $(8,36,47,54)$. So, the PKC isoforms and the inter-isoform regulation might serve as targets for cellular signaling modulation for therapeutic intervention against pathophysiological conditions.

\section{CONCLUSION}

From the evidences gathered, the existence of inter-PKC regulation and a PKC-signaling module seem a logical plausibility. The signaling specificity is generated by the combinatorial assemblies and spatio-temporal dynamics of the PKC isoforms allowing calibration and kinetic modulation of the pathways of the receptor-regulated cellular responsiveness. Although the extreme diversity of PKC responses based on cellular and stimulus differences and the lack of appropriate tools and specific inhibitors pose a major hurdle in building of a generic PKC-signaling map, the analyses provide a conceptual framework placing all $\mathrm{PKC}$ isoforms in a single space-time network 
and a novel principle for devising therapeutic strategies against pathophysiological conditions.

\section{AUTHOR CONTRIBUTIONS}

AM and SR wrote the manuscript and built the figures. DM and BS critically reviewed the manuscript and made the necessary edits. The final manuscript was a result of the joint efforts of all the authors.

\section{REFERENCES}

1. Takai Y, Kishimoto A, Inoue M, Nishizuka Y. Studies on cyclic nucleotide-independent protein kinase and its pro-enzyme in mammalian tissues. I. Purification and characterization of an active enzyme from bovine cerebellum. J Biol Chem (1977) 252:7603-9.

2. House C, Kemp BE. Protein kinase C contains a pseudosubstrate prototope in its regulatory domain. Science (1987) 238(4834):1726-8. doi:10.1126/ science. 3686012

3. Nishizuka Y. Intracellular signalling by hydrolysis of phospholipids and activation of protein kinase C. Science (1992) 258:607-14. doi:10.1126/ science. 1411571

4. Dekker LV, Parker PJ. Protein kinase C - a question of specificity. Trends Biochem Sci (1994) 19:73-7. doi:10.1016/0968-0004(94)90038-8

5. Mochly-Rosen D. Localization of protein kinases by anchoring proteins: a theme in signal transduction. Science (1995) 268:247-51. doi:10.1126/ science.7716516

6. Newton AC. Protein kinase C: structural and spatial regulation by phosphorylation, cofactors and macromolecular interactions. Chem Rev (2001) 101:2353-64. doi:10.1021/cr0002801

7. Freeley M, Kelleher D, Long A. Regulation of protein kinase C function by phosphorylation on conserved and non-conserved sites. Cell Signal (2011) 23:753-62. doi:10.1016/j.cellsig.2010.10.013

8. Sudan R, Srivastava N, Pandey SP, Majumdar S, Saha B. Reciprocal regulation of protein kinase $\mathrm{C}$ isoforms results in differential cellular responsiveness. J Immunol (2012) 188:2328-37. doi:10.4049/jimmunol.1101678

9. Takai Y, Kishimoto A, Kikkawa U, Mori T, Nishizuka Y. Unsaturated diacylglycerol as a possible messenger for the activation of calcium-activated phospholipid-dependent protein-kinase system. Biochem Biophys Res Commun (1979) 91:1218-24. doi:10.1016/0006-291X(79)91197-5

10. Castagna MY, Takai Y, Kaibuchi K, Kikkawa SU, Nishizuka Y. Direct activation of calcium-activated phospholipid-dependent protein kinase by tumor promoting phorbol esters. J Biol Chem (1982) 257:7847-51.

11. Mochly-Rosen D, Khaner H, Lopez J. Identification of intracellular receptor proteins for activated protein kinase C. Proc Natl Acad Sci U S A (1991) 88:3997-4000. doi:10.1073/pnas.88.9.3997

12. Ron D, Chen CH, Caldwell J, Jamieson L, Orr E, Mochly-Rosen D. Cloning of an intracellular receptor for protein kinase $\mathrm{C}$ : a homolog of the $\beta$-subunit of G-proteins. Proc Natl Acad Sci U S A (1994) 91:839-43. doi:10.1073/ pnas.91.3.839

13. Mochly-Rosen D, Khaner H, Lopez J. Identification of intracellular receptor proteins for activated protein kinase C. Proc Natl Acad Sci (1991) 88:3997-4001.

14. Jaken $\mathrm{S}$. An overlay assay for detecting protein kinase $\mathrm{C}$ binding proteins and substrates. Meth Mol Biol (2003) 233:359-68. doi:10.1385/1-59259-397-6:359

15. Steinberg SF. Structural basis of protein kinase C isoform function. Physiol Rev (2008) 88:1341-78. doi:10.1152/physrev.00034.2007

16. Cho W. Membrane targeting by $\mathrm{C} 1$ and C2 domains. J Biol Chem (2001) 276(35):32407-10. doi:10.1074/jbc.R100007200

17. Antal CE, Newton AC. Protein kinase C signalling in health and disease. Biochem Soc Trans (2014) 42:1477-83. doi:10.1042/BST20140172

18. Benes CH, Wu N, Elia AEH, Dharia T, Cantley LC, Soltoff SP. The C2 domain of PKC $\delta$ is a phosphotyrosine binding domain. Cell (2005) 121:271-80. doi:10.1016/j.cell.2005.02.019

\section{ACKNOWLEDGMENTS}

The authors graciously acknowledge Arathi Nayer for her critical suggestions in drawing the figures.

\section{FUNDING}

DM gratefully acknowledges DST- Inspire Faculty program for providing the funds for publishing this opinion.

19. Stahelin RV, Kong KF, Raha S, Tian W, Melowic HR, Ward KE, et al. Protein kinase $\mathrm{C} \theta \mathrm{C} 2$ domain is a phosphotyrosine binding module that plays a key role in its activation. J Biol Chem (2012) 287(36):30518-28. doi:10.1074/jbc. M112.391557

20. Tsai LCI, Xie I, Dore K, Xie L, Del Rio JC, King CC, et al. Zeta inhibitory peptide disrupts electrostatic interactions that maintain atypical protein kinase $\mathrm{C}$ in its active conformation on the scaffold p62. J Biol Chem (2015) 290(36):21845-56. doi:10.1074/jbc.M115.676221

21. Kawakami Y, Kitaura J, Hartman SE, Lowell CA, Siragaman RP, Kawakami T. Regulation of protein kinase C $\beta$ I by two protein-tyrosine kinases, Btk and Syk. Proc Natl Acad Sci U S A (2000) 97(13):7423-8. doi:10.1073/ pnas. 120175097

22. Tabuse Y, Izumi Y, Piano F, Kemphues KJ, Miwa J, Ohno S. Atypical protein kinase $\mathrm{C}$ cooperates with PAR-3 to establish embryonic polarity in Caenorhabditis elegans. Development (1998) 125(18):3607-14.

23. Diaz-Meco MT, Municio MM, Frutos S, Sanchez P, Lozano J, Sanz L, et al. The product of Par-4, a gene induced during apoptosis, interacts selectively with the atypical isoforms of protein kinase C. Cell (1996) 86(5):777-86. doi:10.1016/S0092-8674(00)80152-X

24. Rex EB, Rankin ML, Yang Y, Lu Q, Gerfen CR, Jose PA, et al. Identification of RanBP 9/10 as interacting partners for protein kinase C (PKC) $\gamma / \delta$ and the D1 dopamine receptor: regulation of PKC-mediated receptor phosphorylation. Mol Pharmacol (2010) 78:69-80. doi:10.1124/mol.110.063727

25. Schechtman D, Mochly-Rosen D. Adaptor proteins in protein kinase C-mediated signal transduction. Oncogene (2001) 20:6339-47. doi:10.1038/ sj.onc. 1204778

26. Prekeris R, Mayhew MW, Cooper JB, Terrian DM. Identification and localization of an actin-binding motif that is unique to the epsilon isoforms of protein kinase $\mathrm{C}$ and participates in the regulation of synaptic function. J Cell Biol (1996) 132(1,2):77-90. doi:10.1083/jcb.132.1.77

27. Rode von Essen M, Kongsbak M, Levring TB, Hansen AK, Boding L, Holst Lauritsen JP, et al. PKC- $\theta$ exists in an oxidized inactive form in naive human T cells. Eur J Immunol (2013) 43:1659-66. doi:10.1002/eji.201243140

28. Neeli I, Radic M. Opposition between PKC isoforms regulates histone deamination and neutrophil extracellular chromatin release. Front Immunol (2013) 4:38. doi:10.3389/fimmu.2013.00038

29. Hoshi N, Langeberg LK, Gould CM, Newton AC, Scott JD. Interaction with AKAP79 modifies the cellular pharmacology of PKC. Mol Cell (2010) 37(4):541-50. doi:10.1016/j.molcel.2010.01.014

30. Oancea E, Meyer T. Protein kinase $\mathrm{C}$ as a molecular machine for decoding calcium and di-acyl glycerol signals. Cell (1998) 95(3):307-18. doi:10.1016/ S0092-8674(00)81763-8

31. Urtreger AJ, Kazanietz MG, Bal de Kier Joffe ED. Contribution of individual PKC isoforms to breast cancer progression. Life (2012) 64(1):18-26. doi:10.1002/iub.574

32. Marinissen MJ, Capiati D, Boland R. 1, $25(\mathrm{OH})_{2}$-vitamin $\mathrm{D}_{3}$ affects the subcellular distribution of protein kinase $\mathrm{C}$ isoenzymes in muscle cells. Cell Signal (1998) 10(2):91-100. doi:10.1016/S0898-6568(97)00096-X

33. Dutil EM, Keranen LM, Depaoli-Roach AA, Newton AC. In vivo regulation of protein kinase $\mathrm{C}$ by transphosphorylation followed by autophosphorylation. J Biol Chem (1994) 269(47):29359-62.

34. Murriel CL, Mochly-Rosen D. Opposing roles of $\delta$ and $\varepsilon$ PKC in cardiac ischemia and reperfusion: targeting the apoptotic machinery. Arch Biochem Biophys (2003) 420:246-54. doi:10.1016/j.abb.2003.08.038 
35. Holm A, Tejle K, Gunnarsson T, Magnusson KE, Descoteaux A, Rasmusson B. Role of protein kinase $\mathrm{C} \alpha$ for uptake of unopsonized prey and phagosomal maturation in macrophages. Biochem Biophys Res Commun (2003) 302(4):653-8. doi:10.1016/S0006-291X(03)00231-6

36. Pingel S, Wang ZE, Locksley RM. Distribution of protein kinase C isoforms after infection of macrophages with Leishmania major. Infect Immun (1998) 66(4):1795-9.

37. Loegering DJ, Lennartz MR. Protein kinase $C$ and toll-like receptor signaling. Enz Res (2011) 2011:1-7. doi:10.4061/2011/537821

38. White WO, Seibenhener ML, Wooten MW. Phosphorylation of tyrosine 256 facilitates nuclear import of atypical protein kinase C. J Cell Biochem (2002) 85:42-53. doi:10.1002/jcb.10101

39. Trushin SA, Pennington KN, Carmona EM, Asin S, Savoy DN, Billadeau $\mathrm{DD}$, et al. Protein kinase $\mathrm{C} \alpha(\mathrm{PKC} \alpha)$ acts upstream of PKC $\theta$ to activate IкB kinase and NF-кB in T lymphocytes. Mol Cell Biol (2003) 23(19):7068-81. doi:10.1128/MCB.23.19.7068-7081.2003

40. Thuille N, Wachowicz K, Hermann-Kleiter N, Kaminski S, Fresser F, LutzNicoladoni C, et al. PKC $\theta / \beta$ and CYLD are antagonistic partners in the NFKB and NFAT transactivation pathways in primary mouse $\mathrm{CD}^{+} \mathrm{T}$ lymphocytes. PLoS One (2013) 8(1):e53709. doi:10.1371/journal.pone.0053709

41. Pysz MA, Hao F, Hizli AA, Lum MA, Swetzig WM, Black AR, et al. Differential regulation of cyclin D1 expression by protein kinase $\mathrm{C} \alpha$ and $\varepsilon$ signaling in intestinal epithelial cells. J Biol Chem (2014) 289(32):22268-83. doi:10.1074/ jbc.M114.571554

42. Basu R, Chen Y, Quann EJ, Huse M. The variable hinge region of novel PKCs determines localization to distinct regions of the immunological synapse. PLoS One (2014) 9(4):e95531. doi:10.1371/journal. pone.0095531

43. Fu G, Hu J, Neiderberger-Magnenat N, Rybakin V, Casas J, Yachi PP, et al. Protein kinase $\mathrm{C} \eta$ is required for T-cell activation and homeostatic proliferation. Sci Signal (2011) 4(202):ra84. doi:10.1126/scisignal.2002058

44. Lutz-Nicoladoni C, Thuille N, Wachowicz K, Gruber T, Leitges M, Baier G. PKC $\alpha$ and PKC $\beta$ cooperate functionally in CD3-induced de novo IL2 mRNA transcription. Immunol Lett (2013) 151(1-2):31-8. doi:10.1016/j. imlet.2013.02.002

45. Hassouna A, Matata BM, Galiñanes M. PKC- $\varepsilon$ is upstream and PKC- $\alpha$ is downstream of mitoK $\mathrm{K}_{\mathrm{ATP}}$ channels in the signal transduction pathway of ischemic preconditioning of human myocardium. Am J Physiol Cell Physiol (2004) 287:C1418-25. doi:10.1152/ajpcell.00144.2004

46. Bell KS, Al-Riyami L, Lumb FE, Britton GJ, Poole AW, Williams CM, et al. The role of individual protein kinase $\mathrm{C}$ isoforms in mouse mast cell function and their targeting by the immuno-modulatory parasitic worm product, ES-62. Immunol Lett (2015) 168:31-40. doi:10.1016/j. imlet.2015.09.001
47. Castrillo A, Pennington DJ, Otto F, Parker PJ, Owen MJ, Boscá L. Protein kinase $\mathrm{C} \varepsilon$ is required for macrophage activation and defense against bacterial infection. J Exp Med (2001) 194(9):1231-42. doi:10.1084/jem.194.9.1231

48. Das S, Bhattacharjee O, Goswami A, Pal NK, Majumdar S. Arabinosylated lipoarabinomannan (Ara-Lam) mediated intracellular mechanisms against tuberculosis infection: involvement of PKC mediated signaling. Tuberculosis (2015) 95:208-16. doi:10.1016/j.tube.2014.11.007

49. Holm A, Tejle K, Magnusson KE, Descoteaux A, Rasmusson B. Leishmania donovani lipiphosphoglycan causes periphagosomal actin accumulation: correlation with impaired translocation of PKC $\alpha$ and defective phagosome maturation. Cell Microbiol (2001) 3(7):439-47. doi:10.1046/j.1462-5822.2001.00127.x

50. Bhattacharyya S, Ghosh S, Jhonson PL, Bhattacharya SK, Majumdar S. Immunomodulatory role of interleukin-10 in visceral leishmaniasis: defective activation of protein kinase C-mediated signal transduction events. Infect Immun (2001) 69(3):1499-507. doi:10.1128/IAI.69.3.1499-1507.2001

51. Majumder S, Dey R, Bhattacharjee S, Rub A, Gupta G, Bhattacharyya Majumdar S, et al. Leishmania-induced biphasic ceramide generation in macrophages is crucial for uptake and survival of the parasite. J Infect Dis (2012) 205(10):1607-16. doi:10.1093/infdis/jis229

52. Rub A, Dey R, Jadhav M, Kamat R, Chakkaramakil S, Majumdar S, et al. Cholesterol depletion associated with Leishmania major infection alters macrophage CD40 signalosome composition and effector function. Nat Immunol (2009) 10(3):273-80. doi:10.1038/ni.1705

53. Dey R, Majumder N, Bhattacharjee S, Bhattacharyya Majumdar S, Banerjee $\mathrm{R}$, Ganguly S, et al. Leishmania donovani-induced ceramide as the key mediator of Akt dephosphorylation in murine macrophages: role of protein kinase C $\zeta$ and phosphatase. Infect Immun (2007) 75(2):2136-42. doi:10.1128/ IAI.01589-06

54. Yang CS, Lee JS, Song SH, Hur GM, Lee SJ, Tanaka S. Protein kinase C $\zeta$ plays an essential role for Mycobacterium tuberculosis-induced extracellular signal regulated kinase $1 / 2$ activation in monocytes/ macrophages via toll-like receptor 2. Cell Microbiol (2007) 9(2):382-96. doi:10.1111/j.1462-5822.2006.00797.x

Conflict of Interest Statement: The authors declare that the research was conducted in the absence of any commercial or financial relationships that could be construed as a potential conflict of interest.

Copyright (c) 2016 Mukherjee, Roy, Saha and Mukherjee. This is an open-access article distributed under the terms of the Creative Commons Attribution License (CC $B Y)$. The use, distribution or reproduction in other forums is permitted, provided the original author(s) or licensor are credited and that the original publication in this journal is cited, in accordance with accepted academic practice. No use, distribution or reproduction is permitted which does not comply with these terms. 